\title{
Self-Compatibilization of Polymer Blends Prepared via Concentrated Emulsion Diffusion Polymerization
}

\author{
Zhongjie DU ${ }^{\dagger}$ and Chen ZHANG \\ School of Materials Science \& Engineering, P. O. Box 272, Beijing University of \\ Chemical Technology, Beijing 100029, P. R. China
}

(Received August 19, 2002; Accepted November 6, 2002)

\begin{abstract}
Two concentrated emulsions of styrene (St) and acrylonitrile (AN)/butyl methacrylate (BMA) in water were prepared respectively. Each system contains a small amount of initiator in the dispersed phase. This kind of emulsion has a large volume fraction of the dispersed phase (more than 74.06\%). After the two concentrated emulsions were partially polymerized, they were mixed mechanically and subjected to complete polymerization. Subsequently reactions between the interfaces of different droplets occurred. During the latter diffusion polymerization, a kind of pseudo-block copolymer was generated which constituted the compatibilizers of the blend systems. Elemental Analysis, fourier transform infrared spectra (FT-IR), dynamic mechanical thermal analysis (DMTA), scanning electron microscopy (SEM), transmission electron microscopy (TEM) and mechanical strength were employed to characterize the compatibilization of the polymer blends. The results showed that the blend materials thus obtained possessed excellent compatibilization.

KEY WORDS Concentrated Emulsion / Self-Compatibilization / Blend / Polystyrene / Poly(butyl methacrylate)/
\end{abstract}

Compatibilization is a process of modification of the interfacial properties in immiscible polymer blends, which is a key factor for polymer blends to increase the strength, toughness, and processability ${ }^{1-5}$ Compatibilization can be accomplished by physical or chemical means. Now the latter, including the compatibilization by addition and the reactive compatibilization, has been widely used in the improvement of the compatibilization of polymer blends. ${ }^{6-9}$ In this paper, a novel method of preparation of polymer blend was proposed involving concentrated emulsion diffusion polymerization. A concentrated emulsion has a volume fraction of the dispersed phase that is larger than 0.74 (this represents the most compact arrangement of spheres of equal size). The continuous phase exists in the form of thin liquid film, which separates the polyhedral droplets of the dispersed phase. ${ }^{10-12}$ This group has recently carried out some research work of preparation of core/shell particles, monodisperse particles and polymer composites via concentrated emulsion polymerization. ${ }^{13-16}$ In this paper, the concentrated emulsions of styrene/acrylonitrile (St/AN) system and styrene/butyl methacrylate (St/BMA) system containing a small amount of AIBN initiator were partially polymerized until a suitable viscosity was reached, and then they were mixed mechanically and subjected to complete polymerization. After the two partially polymerized concentrated emulsions were mixed, diffusion of monomers among cells took place. The dif- fusion was slow because the system possessed a relatively high viscosity and the diffusion of the monomers formed a gradient. Subsequently, a kind of gradient block copolymer, namely pseudo-block copolymer of St and AN/BMA was generated via diffusion between the interface of different dispersed phases, which constituted the compatibilizers of polystyrene (PS) and Polyacrylonitrile (PAN)/poly(butyl methacrylate) (PBMA) blend.

The first system, St/AN was employed especially for characterizing the reaction mechanism, because polystyrene and polyacrylonitrile can be separated easily by solvent, for example, the toluene. The second system, St/BMA was employed especially for characterizing the self-compatibilization and mechanical properties of the polymer blends. The effect of compatibilization was evaluated in this paper via elemental Analysis, fourier transform infrared spectra (FT-IR), dynamic mechanical thermal analysis (DMTA), scanning electron microscopy (SEM) and transmission electron microscopy (TEM). For the present system, the higher the conversion of partial polymerization, the better the compatibility. If the conversion of first step further increases, the viscosity of the two partially polymerized concentrated emulsions is too high to be mixed uniformly. This indicates that an appropriate conversion of first step can be obtained for getting an optimal compatibilization of polymer blends.

${ }^{\dagger}$ To whom correspondence should be addressed (Tel: +86-10-64444899, Fax: +86-10-64445930, E-mail: m94037@mail.buct.edu.cn). 
Table I. Results of elemental analysis of toluene insoluble specimens

\begin{tabular}{|c|c|c|c|c|c|}
\hline \multirow[t]{2}{*}{ Sample } & \multicolumn{2}{|c|}{$\begin{array}{c}\text { Time of partial } \\
\text { polymerization }(\mathrm{min})\end{array}$} & \multirow{2}{*}{$\begin{array}{c}\begin{array}{c}\text { Conversion of } \\
\text { partial } \\
\text { polymerization }\end{array} \\
\frac{(\mathrm{wt} \%)}{}\end{array}$} & \multirow{2}{*}{$\begin{array}{l}\text { Toluene } \\
\text { insoluble } \\
(\mathrm{wt} \%)\end{array}$} & \multirow{2}{*}{$\begin{array}{c}\text { Content of } \mathrm{N} \\
\text { element of toluene } \\
\text { insoluble } \\
(\%)\end{array}$} \\
\hline & $\mathrm{St}$ & AN & & & \\
\hline $\bar{a}$ & 22 & 45 & 3.0 & 2.16 & 17.14 \\
\hline b & 38 & 56 & 5.0 & 5.77 & 16.32 \\
\hline $\mathrm{c}$ & 56 & 64 & 7.0 & 8.96 & 15.95 \\
\hline d & 66 & 72 & 9.0 & 13.27 & 10.96 \\
\hline
\end{tabular}

Concentration of SDS $\left(\mathrm{g} / \mathrm{g} \mathrm{H}_{2} \mathrm{O}\right)=0.08$; weight ratio of $\mathrm{St} / \mathrm{AN}=8 / 2$; polymerization temperature: $50{ }^{\circ} \mathrm{C}$; polymerization time: $12 \mathrm{~h}$.

Table II. Recipes for styrene/(butyl methacrylate) system

\begin{tabular}{|c|c|c|c|c|}
\hline \multirow[t]{2}{*}{ Sample } & \multicolumn{2}{|c|}{$\begin{array}{c}\text { Time of partial polymerization } \\
\text { (h) }\end{array}$} & \multirow{2}{*}{$\begin{array}{c}\text { Conversion of partial } \\
\text { polymerization } \\
(\mathrm{wt} \%)\end{array}$} & \multirow{2}{*}{$\begin{array}{c}\text { Feasibility of mixing } \\
\text { after partial } \\
\text { polymerization } \\
\end{array}$} \\
\hline & Styrene & Butyl methacrylate & & \\
\hline $\mathrm{a}$ & 1.4 & 1.1 & 4.5 & feasible \\
\hline $\mathrm{b}$ & 2.3 & 1.8 & 10.5 & feasible \\
\hline $\mathrm{c}$ & 2.7 & 2.1 & 16.5 & feasible \\
\hline d & 3.1 & 2.2 & 22.5 & feasible \\
\hline e & 3.3 & 2.3 & 24.0 & infeasible \\
\hline
\end{tabular}

The weight ratio of the two concentrated emulsions mixed was $1 / 1$. Amount of SDS $(\mathrm{g} / \mathrm{g}$ $\left.\mathrm{H}_{2} \mathrm{O}\right)=0.08$; amount of $\operatorname{AIBN}\left(\mathrm{g} \mathrm{mL}^{-1}\right.$ monomer $)=0.006$; fraction of dispersed phase $=0.8$; polymerization temperature $=50^{\circ} \mathrm{C}$; polymerization time $=12 \mathrm{~h}$.

\section{EXPERIMENTAL}

\section{Materials}

Styrene (St, AR, Shanghai Reagent Manufacturer, China), acrylonitrile (AN, AR, Shanghai Reagent Manufacturer, China) and butyl methacrylate (BMA, AR, Beijing YILI Fine Chemicals Limited Co., China) were filtered through an inhibitor removal column before use. Azobisisobutyronitrile (AIBN, AR, Beijing Reagent Manufacturer No. 3, China) was recrystallized from methanol. The other compounds, sodium dodecyl sulfate (SDS, 70\%, Beijing QIUXIAN Chemical manufacturer, China) potassium bromide (AR, Beijing Reagent Manufacturer No. 2, China) and methanol (AR, Beijing YILI Fine Chemicals Limited Co., China) were used as received.

\section{Preparation Procedures}

An aqueous solution of SDS $\left(0.08 \mathrm{gg}^{-1} \mathrm{H}_{2} \mathrm{O}\right)$ was first placed in a flask provided with a magnetic stirrer. The flask was sealed with a rubber septum, after which the air was replaced with nitrogen. The dispersed phase of St or AN/BMA containing an initiator (AIBN, $0.006 \mathrm{~g} \mathrm{~mL}^{-1}$ monomers) was added dropwise with vigorous stirring into the flask with a syringe, until the volume fraction of the dispersed phase became 0.8 . The whole addition process lasted about $15 \mathrm{~min}$ at room temperature. The two concentrated emulsions thus prepared were partially polymerized at $50^{\circ} \mathrm{C}$ for some time in order to increase the viscosity. Subsequently, the two partially polymerized concentrated emulsions were mixed mechanically, and further heated at $50^{\circ} \mathrm{C}$ for $12 \mathrm{~h}$ to complete the polymerization of the monomers. The blend products obtained were washed with methanol and dried in a vacuum oven.

The various samples prepared are listed in Table I and II.

\section{Fourier Transform Infrared (FT-IR) Spectra}

Infrared study was carried out with a FT-IR instrument (F-1000, Shimatsu, Japan) by using a sample film prepared by thermal pressing of the products with potassium bromide.

\section{Dynamic Mechanical Thermal Analysis}

The thermal behavior of the specimen was determined by dynamic mechanical thermal analysis (DMTA) with a DuPont instrument. The sample was heated from $0^{\circ} \mathrm{C}$ to $200^{\circ} \mathrm{C}$. The heating rate was $10{ }^{\circ} \mathrm{C} \mathrm{min}^{-1}$.

\section{Scanning Electron Microscopy (SEM)}

The fractured surface of the specimen was coated with a thin film of gold. The surface morphology was examined by scanning electron microscope (Hitachi S800). 


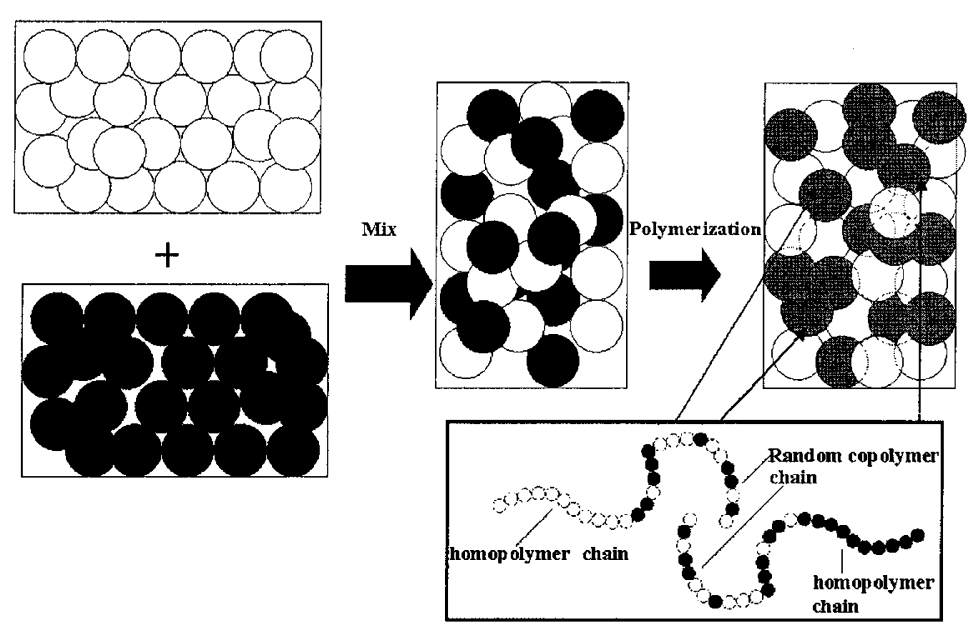

Figure 1. Mechanism of self-compatibilization of polymer blend via concentrated emulsion diffusion polymerization. The white sphere represents the cells of styrene; the black sphere represents the cells of acrylonitrile.

\section{Transmission Electron Microscopy (TEM)}

The powders of the specimen were thermo-pressed with a laboratory press (Shanghai, China) at $160^{\circ} \mathrm{C}$ for $5 \mathrm{~min}$, and then cooled to room temperature. The sheets thus obtained were dyeing with osmic anhydride after subzero microtome. The microstructure was examined by transmission electron microscope (Hitachi, H-8001).

\section{Measurement of Impact Strength}

The impact bars were prepared by injection molding machine. The Izod impact test was performed according to GB/T1043-93 with an XJJ-5 impact tester at $25^{\circ} \mathrm{C}$.

\section{RESULTS AND DISSCUSSION}

\section{St/AN System}

In present system, the volume fraction of the concentrated emulsion is 0.8 , which represents a compact arrangement of droplets. Figure 1 shows the selfcompatiblization mechanism of polymer blends via concentrated emulsion diffusion polymerization. The white spheres and the black spheres represent the different phases separately. After the two partially polymerized concentrated emulsions are mixed, the white and black spheres are accumulated closely. The diffusion of monomers occurs spontaneously between the interface of the white and black spheres. Because the system has a relatively high viscosity, the diffusion of the monomers can be constricted in a thin shell near the surface of sphere and the diffusion of monomers forms a gradient. After polymerization, a kind of pseudo-block copolymer is generated simultaneously, which can be seen in Figure 1.

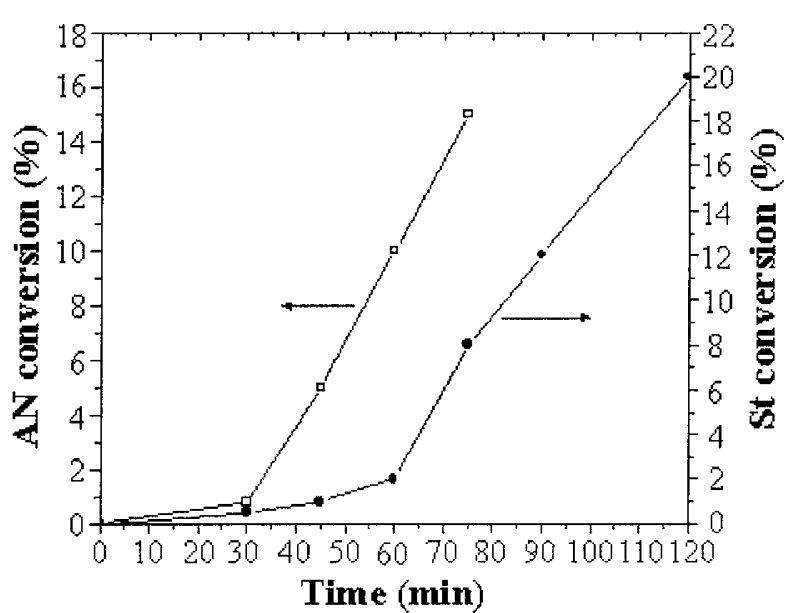

Figure 2. Conversion-time curves of the concentrated emulsions of styrene and acrylonitrile.

In order to examine the self-compatibilization of polymer blends via concentrated emulsion polymerization, the St/AN system was employed. Figure 2 shows the conversion-time curves of styrene and acrylonitrile monomers via concentrated emulsion pathway. According to Figure 2, a partially polymerized conversion of $3.0 \mathrm{wt} \%, 5.0 \mathrm{wt} \%, 7.0 \mathrm{wt} \%$, and $9.0 \mathrm{wt} \%$ was selected as the time of mixing of the two partially polymerized systems. According to the mechanism, the products thus obtained include homopolymer of styrene and acrylonitrile, the random copolymer of styrene and acrylonitrile, the pseudo-block copolymers A (chain segment of homopolymer is polystyrene) and B (chain segment of homopolymer is polyacrylonitrile). Toluene as the solvent, the product thus obtained was washed to remove the homopolymer of styrene, the random copolymer of styrene and acrylonitrile, and the pseudo-block copolymer A. The remained products including homopolymer of acrylonitrile and pseudoblock copolymer B were examined via elemental anal- 
ysis, and the results were showed in Table I.

One may note that the higher the partially polymerized conversion, the lower the nitrogen content, which represents the increasing of the content of pseudoblock copolymer B. When the partially polymerized conversion reached $9.0 \mathrm{wt} \%$, the nitrogen content was $10.96 \%$. The lowest nitrogen content shows the best self-compatibilization of polystyrene with polyacrylonitrile. This is a result of diffusion controlling of monomers between interfaces of different droplets. The high partially polymerized conversion limited the diffusion of monomers among the droplet of concentrated emulsion, which is the key factor to generation of the pseudo-block copolymer in the interface among the droplets of concentrated emulsion. If the partially polymerized conversion exceeded $9.0 \mathrm{wt} \%$, however, the concentration emulsion of acrylonitrile was unstable. As a result, the $9.0 \mathrm{wt} \%$ of partially polymerized conversion was the optimal benefit for the selfcompatiblization for blends of polystyrene with polyacrylonitrile via concentrated emulsion pathway.

\section{St/BMA System}

The velocity and extent of diffusion of the monomers between different droplets is a key factor for the creation of pseudo-block copolymer. This can be controlled by adjusting the viscosity of the blend system. Because the viscosity of the system depends on the conversion of monomers during the partial polymerization, the transfer of monomers after mixing can be controlled easily through the time of partial polymerization. The conversion-time curves of concentrated emulsion polymerization of St and BMA are showed in Figure 3. Figure 3 shows that a conversion of $22.5 \mathrm{wt} \%$ could be achieved after the concentrated emulsion of St was polymerized for $3.1 \mathrm{~h}$ or after the concentrated emul-

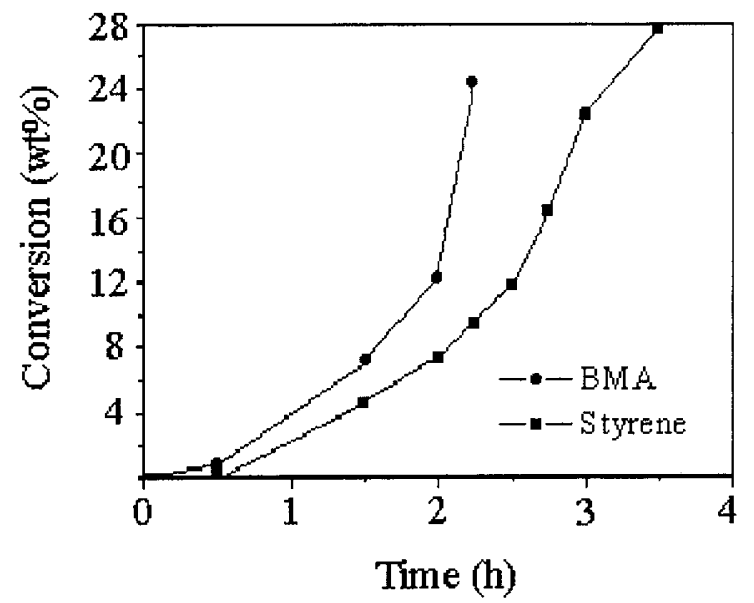

Figure 3. Conversion-time curves of the concentrated emulsions of styrene and butyl methacrylate. sion of BMA was polymerized for $2.2 \mathrm{~h}$. The conversion of $22.5 \mathrm{wt} \%$ provided a suitable viscosity for mixing of the partially polymerized concentrated emulsion. Upon conversion higher than $22.5 \mathrm{wt} \%$, the mixing became difficult, and the two partially polymerized concentrated emulsions could not be mixed uniformly. As a result, the conversion of $22.5 \mathrm{wt} \%$ was considered as the highest conversion for mixing of the partially polymerized concentrated emulsions of St and BMA.

The copolymerization of St and BMA monomers via diffusion between the interfaces of partially polymerized cells was assessed on the basis of the FT-IR spectra (Figure 4). The three spectra in Figure 4 are for the pure PBMA $\left(\mathrm{a}_{1}\right)$, the compound of PBMA and PS via mixing mechanically $\left(\mathrm{a}_{2}\right)$ and the polymer blend of PBMA and PS via concentrated emulsion diffusion polymerization $\left(a_{3}\right)$ respectively. PBMA can be characterized by the sharp peak near $1728 \mathrm{~cm}^{-1}$, pointed by an arrow in Figure 4. One can see that no displacement of PBMA peak occurred after the mixing of PBMA and PS, which represents no reaction between PBMA and PS phase. For specimen $\mathrm{a}_{3}$, however, a displacement of $6 \mathrm{~cm}^{-1}$ wavenumber was found. This indicates the occurrence of diffusion of different monomers and the copolymerization of St and BMA.

In this paper, the DMTA have two purposes: the determination of the glass transition temperatures $T_{\mathrm{g}} \mathrm{s}$ and the assessment of the compatibilization of PS/PBMA polymer blends. The DMTA curves for the samples subjected to the conversion of partial polymerization of $4.5,10.5,16.5$, and $22.5 \mathrm{wt} \%$ are presented in Figure 5. The $E^{\prime}, E^{\prime \prime}$ and $T_{\mathrm{g}} \delta$ represents the real modulus, the image modulus and the tangent of hysteresis angle. One can see that only one $T_{\mathrm{g}}$ was obtained. A compatible polymer blends usu-

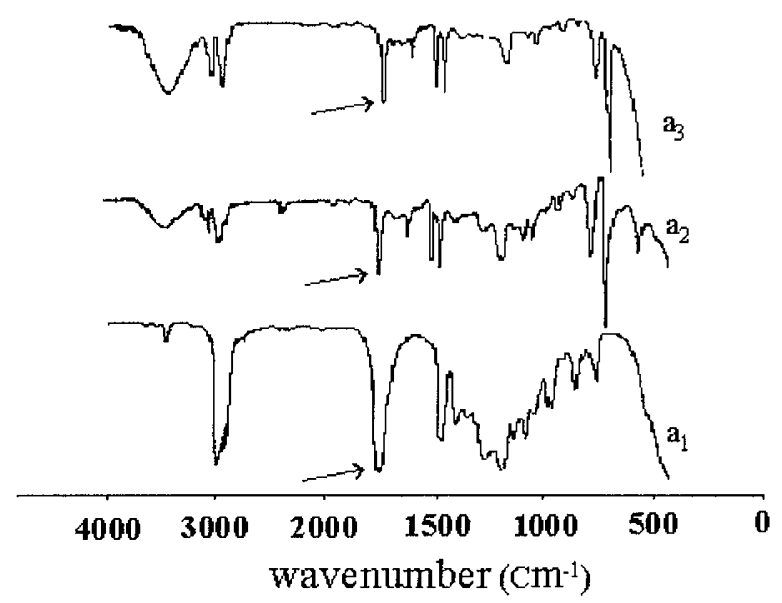

Figure 4. FT-IR spectra of different systems. $a_{1}$ : Sample of pure PBMA; $\mathrm{a}_{2}$ : Sample from compound of PBMA and PS via mixing mechanically; $a_{3}$ : Sample from polymer blend of PBMA and PS via concentrated emulsion diffusion polymerization. 


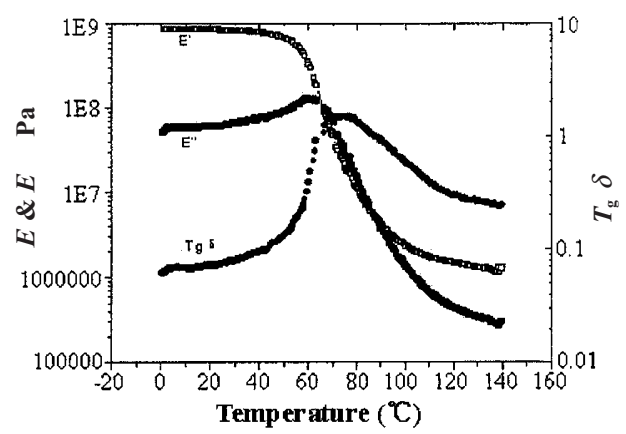

a

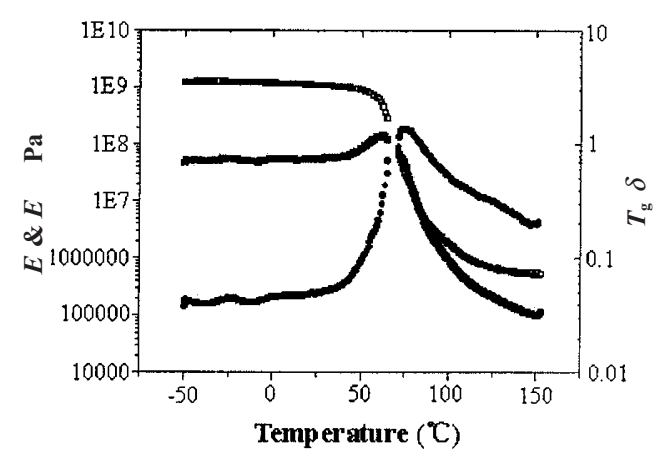

c

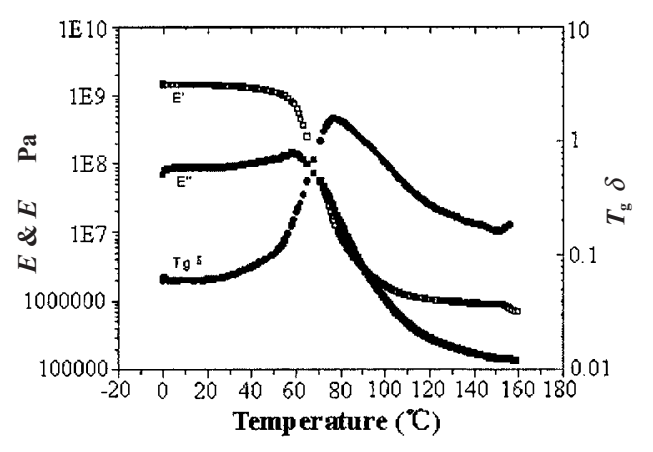

b

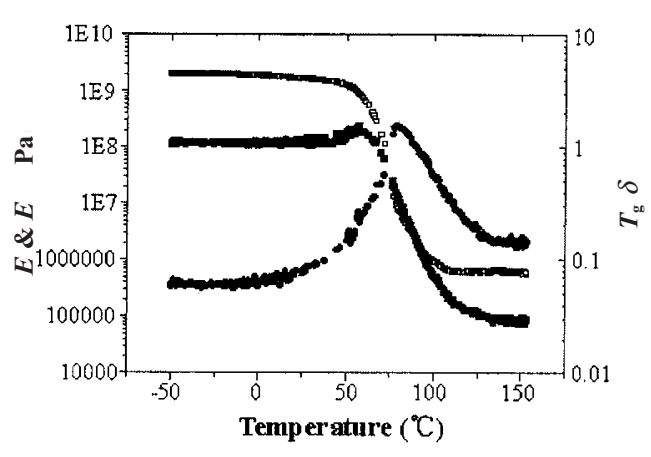

d

Figure 5. DMTA results of different systems. The conversion of partial polymerization (wt\%): a: 4.5; b: 10.5; c: $16.5 ; \mathrm{d}: 22.5$.

ally has a single $T_{\mathrm{g} .}{ }^{17-19}$ This indicates that a selfcompatibility polymer blend of PS/PBMA was obtained via concentrated emulsion diffusion polymerization. One may also notice that the higher the conversion of partial polymerization, the narrower of the peak of $T_{\mathrm{g}} \delta$. This DMTA information indicated that the higher the conversion of partial polymerization, the better the compatiblization of the polymer blends. As a result, one can conclude that the optimum partial polymerization time for St and BMA is $3.1 \mathrm{~h}$ and $2.2 \mathrm{~h}$ respectively. If the conversion of partially polymerization was higher than $22.5 \mathrm{wt} \%$, the mixing of the two partially polymerized concentrated emulsions became difficult and cannot be mixed uniformly.

The compatiblizing effect was revealed clearly by the morphologies of the fractured surface. Figure 6 is micrographs of the fractured surfaces of different PS/PBMA polymer blends. One can notice different smoothness of the surface and the finesse of the wrinkles, from which we can evaluate the compatibilizing effect of the PS/PBMA polymer blends. In Figure 6, sample (a) represents a brittle sample. After breaking, the surface is smooth and the domain size of the phase is large. For sample (b), the fractured surface becomes coarser and the domain size becomes smaller. For the surface of sample (c), it becomes further coarser, and the wrinkles become further finer. The results showed that the higher the conversion of the partial polymeriza- tion, the coarser the fractured surface. Therefore, one can conclude that a better compatibiliation resulted in an increasing of the fracture energy. From the micrographs of Figure 6, we can see that the sample (c) has the best compatibilizing effect.

Figure 7 are micrographs of different PS/PBMA polymer blends obtained by transmission electron microscopy. In Figure 7, the black represents the dispersed phase of PS, and the white represents the continuous phase of PBMA. One can see that when the conversion of partial polymerization increased, the phase size of PS became smaller and the PS phase can be dispersed in the PBMA matrix more uniformly. This is because that when the conversion increased, the diffusion of monomers became difficult and a gradient of diffused monomers was easy to form. In this way, more pseudo-block copolymers and less random copolymers were produced. The incremental amount of pseudoblock copolymers resulted in the improvement of compatibilization of PS/PBMA polymer blends.

The results of impact strength of the PS/PBMA blends are shown in Table III. When the conversion of partial polymerization was $4.5 \%, 10.5 \%, 16.5 \%$, and $22.5 \%$, the impact strength of PS/PBMA polymer blends was $2.20,2.63,2.87$, and $3.22 \mathrm{~kJ} \mathrm{~m}^{-2}$ respectively, which indicated that the impact strength was increased with the increasing of conversion of partial polymerization, which was resulted from the im- 


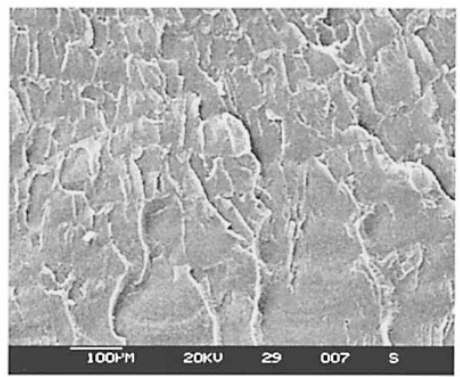

a

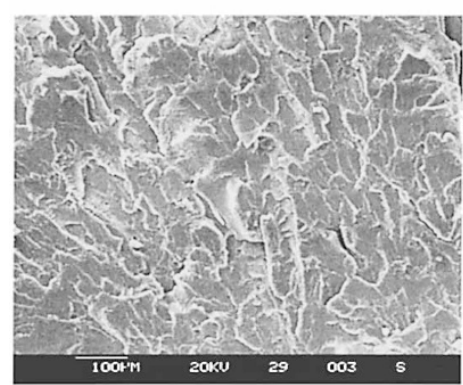

b

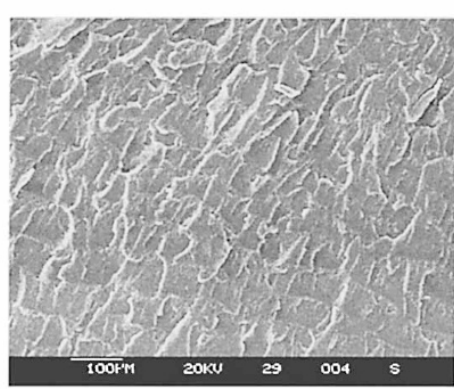

c

Figure 6. SEM micrographs of PS/PBMA blends with different time of partial polymerization. The conversion of partial polymerization (wt\%): a: 10.5 ; b: 16.5 ; c: 22.5 .

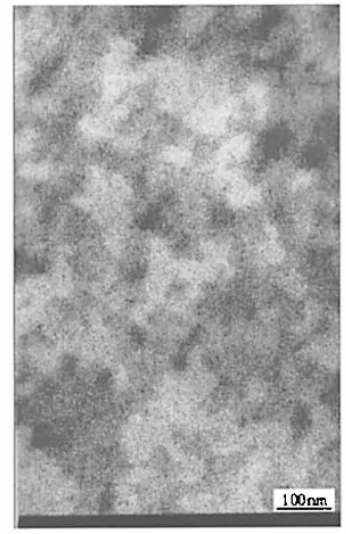

a

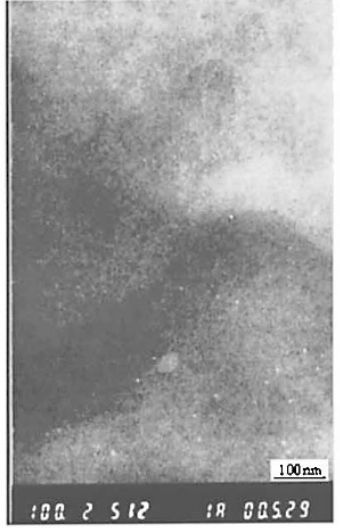

b

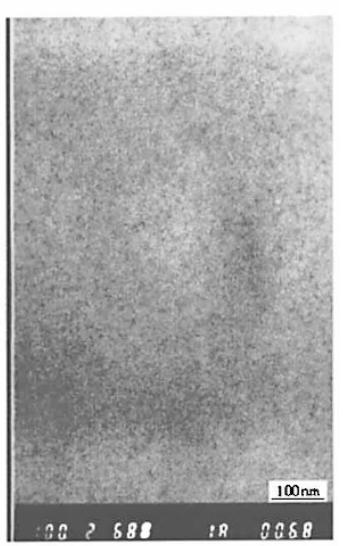

c
Figure 7. TEM micrographs of PS/PBMA blends with different time of partial polymerization. The conversion of partial polymerization (wt\%): a: 10.5 ; b: 16.5; c: 22.5 .
Table III. Mechanical properties of the PS/PBMA blends

\begin{tabular}{ccc}
\hline Sample & $\begin{array}{c}\text { Conversion of partial polymerization } \\
(\mathrm{wt} \%)\end{array}$ & $\begin{array}{c}\text { Impact strength } \\
\left(\mathrm{kJ} \mathrm{m}^{-2}\right)\end{array}$ \\
\hline $\mathrm{a}$ & 4.5 & 2.20 \\
$\mathrm{~b}$ & 10.5 & 2.63 \\
$\mathrm{c}$ & 16.5 & 2.87 \\
$\mathrm{~d}$ & 22.5 & 3.22 \\
\hline
\end{tabular}

provement of compatibilization of PS/PBMA polymer blends.

\section{CONCLUSION}

Two concentrated emulsions of styrene and acrylonitrile/(butyl methacrylate) as the dispersed phase in water were prepared separately. After partial polymerization, they were mixed and subjected to complete polymerization. A kind of pseudo-block copolymer was generated near the surface of the cells simultaneously, which constituted the compatibilizer of polystyrene and polyacrylonitrile/poly(butyl methacrylate) blends. A novel mechanism of compatiblization was proposed. A series of PS/PAN (PS/PBMA) blends with various time of partial polymerization were prepared and their compatibilization and processability were characterized by elemental analysis, fourier transform infrared spectra, dynamic mechanical thermal analysis, scanning electron microscope, transmission electron microscope and mechanical strength. The results showed that the PS/PAN and PS/PBMA blends with a prepolymerized conversion of $9.0 \mathrm{wt} \%$ and $22.5 \mathrm{wt} \%$ possessed the optimal compatibility separately. 
Acknowledgment. This work was supported by Beijing Foundation of Nature Science Grant 2022016.

\section{REFERENCES}

1. L. A. Utracki, Polymer Blends, 11, 10 (2000).

2. I. Akiba, Y. Ohba, Y. Kobori, and S. Akiyama, Polym. J., 32, 402 (2000).

3. M. Hosokawa and S. Akiyama, Polym. J., 31, 13 (1999).

4. A. Habi and S.Djadoun, Eur. Polym. J., 35, 483 (1999).

5. E. V. Sanchez, J. L. Ribelles, M. M. Pradas, B. R. Figueroa, and F. R. Colomer, Eur. Polym. J., 36, 1893 (2000).

6. L. Nie, R. Narayan, and E. A. Gruike, Polymer, 36, 2227 (1995).

7. P. A. Toensmeier, Modern Plastics International, 25, 24 (1995).

8. M. Matsuda, EP 664320, July 26, 1995.

9. M. K. Akkapeddi, J. H. Gland, and J. F. Parmer, U. S. Patent,
5391640, (Feb. 21, 1995).

10. H. Li and E. Ruckenstein, Polymer, 36, 2281 (1995).

11. C. Zhang, Z. Du, and H. Li, Polymer, 43, 2945 (2002).

12. H. Li, J. Zhao, and E. Ruchenstein, Colloids Surf., A, 161, 489 (1999).

13. H. Li and E. Ruckenstein, J. Polym. Sci., Part A: Polym. Chem., 39, 757 (2001).

14. H. Li, Z. Du, and H. Huang, J. Appl. Polym. Sci., 83, 2915 (2002).

15. H. Li, Z. Du, and E. Ruckenstein, J. Appl. Polym. Sci., 68, 999 (1998).

16. H. Li and E. Ruckenstein, Polymer, 37, 3373 (1996).

17. T. O. Ahn, B. U. Nam, M. Lee, and H. M. Jeong, Polymer, 38, 577 (1997).

18. C. H. Choi and B. K. Kim, Eur. Polym. J., 31, 705 (1995).

19. S. H. Hwang, J. C. Jung, and S. W. Lee, Eur. Polym. J., 34, 949 (1998). 